\title{
Information Technology Student-Based Certification in Formal Education Settings: Who Benefits and What is Needed
}

\author{
Michael H. Randall and Christopher J. Zirkle \\ The Ohio State University, Columbus, Ohio, USA
}

\author{
randall.49@osu.edu zirkle.6@osu.edu
}

\section{Executive Summary}

There is a growing trend within secondary and post-secondary institutions to offer information technology (IT) certification programs as instructional vehicles to provide students with viable skills needed by the workforce, to satisfy state skill standards, and to prepare students for postsecondary IT studies. The use of IT certification programs in a formal education setting carries a number of salient issues and implications for educational institutions, IT teachers, administrators, students, and, ultimately, the IT workforce.

Chief among these issues for both secondary and post-secondary institutions is that formal education institutions lack available data to determine the effectiveness of certification programs on a district, state, and national level. There is a need to collect and share IT certification program data to facilitate comparative analyses across formal educational institutions that are using certification programs or preparation. IT instructors and administrators may be making curriculum programming decisions that are based on a variety of information, some of which may be based more on marketing and convenience than specific program information, such as passage rates on examinations, preparation for post-secondary studies, and job placement opportunities. Making informed curriculum decisions about initiating, maintaining, or terminating IT certification programs also requires an understanding of the current IT workforce and future employment projections to ensure the marketability of students and their prolonged success in the IT workforce.

The relative impact that an IT certification has on a student's success depends largely on the educational level at which students obtain a certification. A student that has obtained a certification as an addition to a post-secondary education has a strong theoretical foundation to build on, an increased marketability, and better chances for long term career success. The impact that an IT certification will have on a high school graduate's success in the workforce and long-term career prospects is limited. As opposed to post-secondary graduates, high school graduates lack a strong theoretical foundation and previous experience to draw from when faced with new technologies.

Material published as part of this journal, either on-line or in print, is copyrighted by the publisher of the Journal of Information Technology Education. Permission to make digital or paper copy of part or all of these works for personal or classroom use is granted without fee provided that the copies are not made or distributed for profit or commercial advantage AND that copies 1) bear this notice in full and 2) give the full citation on the first page. It is permissible to abstract these works so long as credit is given. To copy in all other cases or to republish or to post on a server or to redistribute to lists requires specific permission and payment of a fee. Contact Editor@JITE.org to request redistribution permission.
Different categories of IT certifications may be more suitable at different educational levels. A vendorspecific certification may be more beneficial and appropriate for postsecondary students in computer science and business degree programs because of the value it adds to their degree in terms of reflecting current technology and marketability. Vendor-neutral IT certifications may be 
more suitable for high school students because they focus on foundational concepts relative to underlying technology and not on a particular vendor's product. Consequently, high schools that implement vendor-specific certifications may be putting students at a disadvantage both academically and in the workforce.

Unlike community colleges, four year post-secondary institutions have been slow to offer students the added benefit of pursuing an IT certification as a compliment to their degrees. Although integration of certification preparation into traditional computer science and business degree programs can be seen as reflecting current technology and giving students improved employment prospects, both structural and perceptual issues have to be considered.

In the following sections of this paper we present a critical look at IT certification, focused primarily on a U.S. perspective and issues surrounding its use in formal education settings. More specifically, this paper is designed as a research review and will summarize current research surrounding the IT certification in general and in relation to secondary and post-secondary settings, discuss IT literacy and skill standards and their relationship to IT certification programs, review categories of IT certifications, discuss current and future trends of the IT workforce and implications for certification, describe the partnerships and benefits among vendors and educational institutions, and finally present conclusions and recommendations.

Keywords: Information technology, IT certifications, IT curriculum, vendor-specific, vendor neutral, technological literacy, workforce development.

\section{Introduction}

The growth and use of IT and the resulting demand for workers with specialized skills have placed a considerable demand on the traditional educational system to provide a qualified and sustainable IT workforce. According to the U.S. Department of Labor statistics (2004), information technology is the fastest growing sector in the economy with a projected $68 \%$ increase in growth rate between 2002 and 2012. In response to advances in computer technology, rapidly deprecating skill sets, and the slow response of traditional education, the IT industry uses certification as a way to train and accredit its own (Clarke, 2001). Cantor (2002) defines certification "as a confirmation of one's adequate knowledge and skills in a specified occupation or occupational specialty." Further, Cantor classifies IT certifications into two areas: (1) certifications issued by industry that are product-related and (2) certifications issued by organizations or professional associations.

In 1989, Novell created the first IT certification in response to a lack of trained individuals to support their mission critical tasks and the inability to turn to the traditional educational system for a trained supply of workers (Ziob, 2000). IT certifications have since grown as a result of the need for the IT industry to support its products and services (Computer Science and Telecommunications Board, 2001). As of January 2000, 2.4 million IT certifications have been awarded worldwide (Adelman, 2000a), and there are more than 120 IT vendors offering more than 1000 IT certifications (Rowe, 2003). IT certifications are developed by professional, trade, and industry associations as well as independent vendors and can be grouped into two general categories: vendor-specific and vendor-neutral. Vendor-specific certifications and curricula are developed and monitored by a particular vendor and focus primarily on an IT-related discipline surrounding a company's technology, service, and product line. Vendor-neutral certifications are developed and monitored by a consortium of experts from industry, public, and private sectors, and focus on methodology and technology surrounding a particular job role.

Obtaining a certification requires that an individual pass a criterion referenced assessment, acknowledging the attainment of specific skills (Carnevale \& Desrochers, 2001). IT certification assessments are administered by the vendor or third party testing firm, and many vendors require 
that certificate holders re-certify after a specified period of time to demonstrate continued competency (Cantor, 2002). Certification vendors do not require students to provide poof of preparation before attempting an exam and, unlike the preparation for traditional course work given in formal education settings where curricular materials leading up to the exam are prescribed, the choice of preparation vehicles is left to the student (Koziniec \& Dixon, 2002). Preparation vehicles for IT certification exams might include computer-based training, books, CDs, simulation software, exams cram sessions, vendor sponsored curricula, and instructor-led training offered at formal and non-formal educational institutions. IT certification vendors may suggest exam preparation materials or even provide proprietary IT curriculum at a cost to students and educational institutions.

The rapid pace at which technology evolves creates a need for highly skilled individuals to enable, apply, support, configure, and adapt IT products and services. Because IT certifications represent a standard measurement for specific IT skills, companies are seeking out professionals with these credentials (Al-Rawi, Lansari, \& Bouslama, 2005). IT certification programs are considered by many to be responsive to industry needs and providing up-to-date, relevant training for continuously changing skill sets. Industry-based IT certification have become a standard precursor to employment for many IT job roles serving as an indication to human resource managers that specific precursory knowledge or competencies have been met. IT certification is thought to provide a verification of skills and knowledge related to a broad or specific type of technology, hardware, software, or IT product.

In an effort to respond to rapid technological changes and to provide students with curriculum that reflects current technology and practice, educational institutions partner with IT vendors and professional associations to offer IT certification training (Computer Science and Telecommunications Board, 2001). Once authorized by a certification entity to deliver their curriculum, secondary and post-secondary institutions are permitted to use a variety of pre-packaged instructional materials that can include software, hardware, self-study materials, online courseware, lab exercises, practice exams, assessment tools, student communities, and technical support. Turnkey IT curriculums from vendors such as Cisco, Oracle, Prosoft, and Microsoft, come at varying costs for schools and carry different participation requirements (Sands, 2003). As Carew and Flynn (2002) noted, if there is to be a true infusion of appropriate and contemporary IT content in current educational offerings, partnering between industry and academia needs to be increased.

\section{Significance}

This paper will frame the issues surrounding the use of IT certification programs and preparation in both secondary and post-secondary education to give IT teachers and administrators the ability to make better decisions concerning, (1) initiating IT certification programs in secondary schools or integrating them into post-secondary computer science degrees, (2) phasing out ineffectual IT certification programs, (3) aligning IT curriculum with current workforce indicators and projected labor demands, and (4) implementing either vendor-neutral or vendor-specific programs or maintaining an independently designed curriculum that will provide students with the best chances of success in the workforce. Finally, the paper seeks to highlight the need to collect and share IT certification program data to facilitate comparative analyses across formal educational institutions that are using IT certification programs or are preparing students to take certification exams.

\section{Research on IT Certification}

Although IT certification programs present themselves as turnkey solutions for schools interested in giving their graduates an edge in the workforce or satisfy technology competencies, there are concerns that many IT certification programs do not provide the foundation and skills in IT necessary to be successful in a long-term career or in post-secondary studies. A U.S. Department of Commerce (2003) report suggested that IT certifications that satisfy a focused IT skill set do not 
adequately prepare students to obtain mid-to high-level positions in the IT employment sector. The position that an individual obtains when attempting to enter IT workforce is limited by the amount of previous work experience in IT and the amount of formal education acquired. The lack of formal education limits the range of career opportunities, and secondary students entering the IT workforce without further formal education may find that their employment is short-lived with limited career opportunities (Bartlett, 2002).

Since many of the certification programs are narrowly focused on a particular product or technical specialty, there are many considerations that need to be taken into account so as to influence IT curriculum development in a positive way. According to the U.S. Department of Commerce (2003), educational institutions using IT certification programs as a substantial part of their IT curriculum may not be able to respond to new skill demands when the IT industry changes. Many of today's IT curricula that are certification based do not reflect multi-vendor computing and open source software environments that a student will encounter in the workforce. The wellestablished IT business model is rapidly changing and vary rarely will an organization use only one vendor's hardware, software, or technology to build its IT infrastructure. Building an IT curriculum around a particular vendor may put students at a disadvantage both academically and in the workforce.

Obtaining an IT certification can carry a number of advantages or disadvantages depending largely on the nature and type of IT certification, the demand of the IT workforce, and the amount of formal education. Al-Rawi, Lansari, and Bouslama (2005) indicated that students are more marketable when entering the workforce with IT certifications added to their education. Certifications provide IT professionals with ongoing education to learn new technologies and maintain their effectiveness in a particular job role. In contrast, Zeng (2004) points out some disadvantages of IT certification to include, (1) a lack of a single standard for certification because preparation is offered by several organizations, vendors, and educational institutions, (2) some employers may recognize IT certification and others may not, (3) individuals are required by many certification vendors to re-certify every 2-3 years as technology evolves, and (4) a certification may loose its value as a result of both technology changes and as the number of people obtaining a certification increases.

Human resource managers have typically used IT certifications as an indicator of an applicant's base-line suitability for a specific IT related position. Certifications act as a signal to hiring managers that a job candidate has achieved a level of knowledge and skill necessary to perform in a particular IT job role. A recent study sought to determine if human resource managers (HR) and IT professionals perceived IT certifications differently in the context of the hiring process (Cegielski, 2004). The findings of the study indicated that human resources managers placed a greater emphasis on IT certifications when hiring for IT related positions than do IT professionals. Analysis of the data also indicated that IT certifications presented a justification for human resource professionals to make hiring decisions and showed that their reliance on certification as indicators of competence in a job role may account for their perceived value of IT certifications.

The question of whether certified individuals are better able to perform in an IT job-role than non-certified individuals becomes relevant in the hiring process. Cegielski, Rebman, and Reithel (2003) conducted a study comparing network end-users' perceptions of local area networks managed by certified network administrators to network end-users' perceptions of local area networks managed by non-certified network administrators. The purpose of the study was to determine if certified network administrators significantly affected the end-users' perceived attitudes towards network usefulness and ease of use. The data for the study was gathered from 299 subjects from eleven different financial services firms. Six of the eleven firms, representing 173 end-users, had networks managed by a certified network administrator. The findings of the study indicated that no significant difference exists for either perceived usefulness or perceived ease of use among 
between end-users of networks managed by certified network administrators and end-users of networks managed by non-certified network administrators. The findings provide support in contrast to the assumption that an individual holding a certification is a better facilitator of technology than a non-certified individual. The study further points out that certification should not be used as the sole indication of competency or level of compensation in a hiring decision.

In a study of Cisco Academy teachers in urban, rural and suburban districts in northern Illinois, Thompson (2003) reported the success rate of high school students taking the Cisco Certified Network Associate (CCNA) exam, and the teacher's perceived reasons for high or low passing rates. The 53 teachers surveyed were responsible for 1,788 enrolled Cisco Academy K-12 students. The study found that out of the 1,788 students enrolled in the Cisco Academies, only 18 took and passed the CCNA exam, a one percent success rate. Thompson criticized the Cisco Academy CCNA curriculum for only preparing one percent of students for success and suggested that the Cisco CCNA IT curriculum is not suited for high school students and is better suited for post-secondary study.

Students pursuing IT certification programs may not be informed of the role that previous experience and formal education plays in obtaining IT employment. Certification alone is not a panacea, and next to education, previous experience is one of the most important factors in obtaining IT related employment. The Computer Science and Telecommunications Board (2001) suggested that educational institutions provide IT classroom instruction in conjunction with practical workplace experience, as both are necessary in the education of an IT student. Students that hold a certification and have experience carry more weight on a job interview than a high school graduate with a certification and no experience. Hiring managers indicate that the best background for IT employment is previous experience in a related field (46\%) and a four year college degree $(41 \%)$ (Information Technology Association of America [ITAA], 2004).

\section{Post-secondary research on IT certification}

Much of the research on the use of IT certification in post-secondary settings (Al-Rawi, Lansari, \& Bouslama, 2005; Koziniec \& Dixon 2002; Minch \& Tabor, 2003; Zeng, 2004) has proposed different solutions for integrating IT certification preparation into traditional computer science programs. Several two and four-year post-secondary institutions have integrated IT certification preparation into their traditional curriculums or are currently developing criteria to implement certification opportunities for students that overcome the various obstacles and risks to adoption. Students pursuing post-secondary programs in computer science want to be prepared to take and pass IT certifications in addition to earning their degrees to be competitive and meet the demands of the workforce (Zeng, 2004). Although many two-year degree programs offer practical training to prepare students to take IT certification exams, four-year colleges have been slow to follow.

Various integration issues faced by post-secondary institutions that are contemplating initiating an IT certification program into their offerings were examined by Koziniec and Dixon (2002). The dilemma of providing the same certification preparation at both the secondary and postsecondary levels raised questions about course equivalence. Vendor certification programs usually dictate both the content and delivery time of the curriculum and provide ready-made assessments, so the difficulty arises when trying to differentiate between different educational levels using the same certification program. Koziniec and Dixon (2002) further assert that (1) IT certification may be perceived as too vocational for the university level, (2) vendor-sponsored curricula may carry an overt amount of marketing for the vendor's product, (3) the limited lifespan of IT certifications place pressure on instructors to achieve re-certification, and (4) certification exams are usually based on multiple choice questions that test memory and not reasoning or skills and may not be a reliable indicator to employers of a student's ability to perform in an IT job role. 
Many four-year colleges such as the University of Arizona, Penn State University, and California State University at Fresno are forgoing mainstream certification training for their students and instead developing their own certificate training programs. Minch and Tabor (2003) detailed a new degree program in Networking and Telecommunications at Boise State University that is designed to overcome the slow response to the needs of students and more appropriately meet the demands of the IT workforce. Although critical of higher education's response to IT education needs, Minch and Tabor (2003) noted that IT certification programs were not a viable option for their program because they presented significant limitations based on their focus on transient knowledge and skills related to vendor-specific technology. The authors also acknowledged that "while [certification] may meet immediate needs in some organizations, it is an insufficient foundation upon which to base a long-term adaptable work force for an information economy" (p.53).

Al-Rawi, Lansari, and Bouslama (2005) proposed an approach to integrate the objectives of the Sun Certified Programmer for JAVA certification into a post-secondary programming course in an effort to make it more current and responsive to the workforce. After completion of the course students would have received four credits in an information systems programming course and be prepared to sit for the Sun JAVA certification. The researchers noted that over 1000 Java text books were available for their use but none of them explicitly addressed all the certification objectives and object oriented programming concepts needed in class. After selecting a textbook that satisfied many of the course objectives, the researchers developed a syllabus that mapped the Sun certification objectives into the table of contents of the text book. At the completion of the class the students and the author took the Sun certification exam, and two-thirds of the class passed. This proposed approach took no more than a review and selection of an appropriate text and a modification of the index to include certification objectives. There was also a compromise on the part of the instructor to drop course objects that were not critical for the certification in order to fit necessary topics into a course timeline. This approach, although simple, does not address many of the concerns inherent in integrating certification programs in a post-secondary program addressed by Koziniec and Dixon (2002), Minch and Tabor (2003) and Zeng (2004).

Operating a facility to deliver an IT certification training program can be quite costly for a college or university to start and maintain. In addition, logistics and implementation of student certification testing can present obstacles for students and colleges offering these programs. Zeng (2004) proposed and implemented a three-step Computer Information System Associate Degree Program designed to bridge students from an academic program to a training program offered by a thirdparty training and testing center. The first step of the program exposes students to both liberal arts and computer information systems courses to provide a theoretical foundation in IT. In the second step, students follow a focused series of hands-on courses geared toward their choice of certification job role. Students are then directed to third-party training programs offered by certified training and testing centers. Zeng (2004) maintains that a collaborative approach with a third-party training/testing centers benefit (1) the college by avoiding the financial obligations of having to set-up and maintain a training facility and ongoing faculty training, and (2) the students by providing access to the most advanced and current training and assessment material. This approach to integrating certification training into traditional computer systems programs, although beneficial to the college, has the potential of adding significant financial obligations to the student incurred by using third-party training centers.

\section{Information Technology Literacy and Skill Standards}

It has been noted that high schools play and important role in providing students with computer literacy and preparing them for the global IT workforce (Csapo, 2002). Imparting basic IT skills to students is essential in order for them to function in academia, in the workforce, and in everyday activities. With todays technological society, basic computer literacy is emphasized in na- 
tional, state, and district standards, and is many times offered as both a stand-alone core competency, in addition to being integrated into all other core curriculum content areas. There are many reasons for offering specific types and levels of IT certifications. Chief among these reasons is that the global workforce is demanding greater technical literacy from our secondary and postsecondary graduates. Although this is recognized by academia and business leaders, there are no universal criteria or standards in place used to measure computer literacy.

Each state has the task of devising their own criteria by which to validate students' computer literacy. Developers and writers of technology content standards for many states base their own standards on national standards such as The National Workforce Center for Emerging Technologies (NWCET), Standards for Technological Literacy (International Technology Education Association -ITEA), National Educational Technology Standards for Students (International Society for Technology in Education - ISTE), and the Information Literacy Standards for Student Learning (American Association of School Librarians and Association of Educational Communications \& Technology - AASL/AECT).

\section{National Workforce Center for Emerging Technologies}

The National Workforce Center for Emerging Technologies (NWCET) has developed a wellestablished set of skill standards to guide education policy makers and secondary and postsecondary educators in their development of IT content standards. NWCET's standards are particularly well-suited for development of IT skill standards and curriculum development carrying an IT certification component. Education decision makers and educators can use skill standards to develop curriculum that appropriately matches the expectations of the hiring managers in turn ensuring more competitive, employable students. Many traditional two-year and four-year colleges can benefit from using NWCET's standards to integrate certification preparation into their information systems degree programs. NWCET (2003) skill standards are characterized by the following benefits:

1. Skill standards provide a common framework for communication of workplace expectations among business, education, workers, students and government.

2. Skill standards facilitate the reform of education to match curriculum development to workplace requirements.

3. Competency-based standards will assure the employability of students who have completed programs based on those standards.

4. National recognition of skill standards in career fields will provide a common basis for certifying achievement against those standards, thereby allowing for portability of skills across companies and careers.

5. Skill standards will provide workplace expectations so students will know what they need to be able to do to meet those expectations. (p. 5)

The NWCET (2003) defines skill standards as “... the agreed-upon, industry-identified knowledge, skills, and abilities required to succeed in the workplace" (p.2). Skill standards form a necessary framework for the development of relevant curriculum, training, certification, and assessment for use in preparing students to effectively compete in today's global workforce.

NWCET defined skill standards for eight career clusters in information technology. Career clusters are groupings of representative job titles, related by a common set of technical skills, knowledge and abilities. The NWCET (2003) career clusters are:

1. Database Development and Administration

2. Digital Media 
3. Enterprise Systems Analysis and Integration

4. Network Design and Administration

5. Programming/Software Engineering

6. Technical Support

7. Technical Writing

8. Web Development and Administration (p. 13)

NWCET emphasized the important role that industry, government, and educators play in the education of students and pointed out that skill standards help educators to develop curriculum, transfer pathways, professional development, and to develop institutional response priorities. Skill standards also help educators to bridge technical and academic programs, provide targeted instruction, and research curriculum and instruction issues.

\section{International Society for Technology in Education}

The International Society for Technology in Education (ISTE), the largest educational technology organization, published their National Educational Technology Standards (NETS) in 1998 for students and in 2000 published technology standards for teachers (ISTE, 2004). Roblyer (2000) asserted that national technology standards are an important part of the process to defining technological literacy for states. Further, he suggested that a possible strategy for bringing districts and states in line with national technology standards might be to require that they have plans for incorporating or adopting technology standards before participating in federal funding programs. Barron, Kemker, Harmes, and Kalaydjian (2003) noted that as of March 2003, 29 states had aligned with ISTE standards as a guideline in the development of their technology standards.

\section{Motivations to Implement IT Certification Programs}

School administrators are responding to national, state, and district technology standards and policy by offering IT certification programs as instructional vehicles. Training students for the workforce and providing them with IT skills needed to compete in post-secondary education is adequate justification for administrators to implement an IT certification program. Career and technical programs in secondary schools offering IT certification programs either as a stand alone program or as part of an IT academy gain the benefit of attracting students and increasing enrollment. Students excited by the prospect of working with cutting edge technology and the possibility of obtaining an IT certification and entry-level employment readily pursue these programs. As an example of the popularity of IT certification programs in secondary education, 115,570 students enrolled in 4,757 Cisco Networking Academies in the United States with 45\% of the academies located in K-12 institutions as of 2002 (U.S. Department of Commerce, 2003).

School boards have a degree of authority over curriculum decisions, but it is not likely that they are knowledgeable in technical education, so, consequently, decisions regarding IT curriculum implementation are likely based on administrator recommendations (Andero, 2001). Justification for administrators to implement an IT certification program comes from the idea that these programs will (a) train students to enter the workforce or provide them with IT skills needed to compete in post-secondary education, (b) satisfy national, state, and district technology and IT skill standards, and (c) will increase enrollment numbers needed to secure state funds. There are many factors that play a role in influencing decisions to initiate, retain, or terminate a particular IT certification program, but these decisions are not necessarily data-driven. Currently, there are no national or state centralized data collection efforts surrounding IT certification programs in formal education settings. 
According to Andero (2001), it is not likely that school board members are knowledgeable in career and technical education, and consequently, decisions regarding IT curriculum implementation lies with school administrators. Further, he asserted that decisions about curriculum are rarely made that are based on an analysis of program data or that take societal needs into consideration. Many factors may influence secondary school administrators to initiate, retain, or terminate a particular IT certification program. IT certification programs have become deeply entrenched in many formal education settings as a result of a combination of successful marketing efforts from IT vendors, such as Microsoft and Cisco, and the need for educational institutions to satisfy technical standards and recruit students. Secondary and post-secondary institutions often make decisions to offer IT certification programs based on little or no data of what current workforce needs are with respect to formal education, experience, IT skills, and types of certification needed. Zeng (2004) asserts that "the role of certification testing should be examined, evaluated, and determined by those in charge of implementing the program." Further, he suggests that institutions implementing these types of IT certifications need to keep them current and responsive to workforce needs through ongoing professional development for instructors, continuous curriculum revision, periodic review and assessment of programs and equipment, updating instructional methodologies, and gathering student and graduate feedback. Information is needed to better understand how these categories of certifications are perceived by secondary school IT instructors, administrators, and IT professionals to better align student outcomes with workforce and educational needs.

\section{Categories of IT Certifications}

Certification can be defined in terms of a signal that an individual has obtained adequate knowledge and skills in a specified occupation or occupational specialty (Cantor, 2002). Cantor (2002) classifies certification into two areas: (1) certifications issued by industry that are product-related and (2) certifications issued by organizations or professional associations. Vendor-specific IT certifications came about as a way to support products, increase market share, and build a knowledgeable sales force and are associated with branded technology from a particular company, such as Cisco, Microsoft, Novell, and IBM, that focus on proprietary technologies and platforms. Popular vendor-specific certifications include the Cisco Certified Network Associate (CCNA) and the Microsoft Certified Systems Engineer (MCSE). Vendor-neutral certifications are offered by consortiums, nonprofit organizations, and industry associations. They revolve around key concepts and job roles and do not focus on a particular vendor's product or technology (Prosoft Learning, Inc., 2005). Examples of vendor-neutral certifications include Computing Technology Industry Association's (CompTIA) A+, and Prosoft's CIW Web Developer.

\section{Vendor-Specific Certification}

Tittel (2000) pointed out that a population of individuals certified in a vendor-specific, productbased technology benefits companies by (a) reducing in-house technical support costs; (b) promoting the products and technology they are certified to support; (c) pushing old software and hardware versions to new releases; and (d) by requiring recertification of its allegiance of certification holders. Bird (2001) notes the advantages of vendor-specific certification programs:

1. Vendor-specific programs provide detailed instruction on specific technologies and products.

2. They enjoy industry-wide recognition relative to product popularity.

3. They focus curriculum on current and widely used products.

4. Generally speaking, more supporting material such as books, training materials and forums are available for vendor-specific programs. 
Information Technology Student-Based Certification

5. Some vendor-specific certifications are generally recognized on a worldwide basis, whereas certain vendor-neutral certifications are administered by localized organizations.

6. Vendors are able to prepare curriculum for products before their release, allowing programs to closely match industry trends.

Vendor-specific certifications used in formal education settings include Microsoft Certified Professional, Microsoft Certified Systems Engineer, Certified Novell Engineer, Sun Certified Java Developer, and the Macromedia Certified Dreamweaver MX Developer, to name a few. Individuals that need an understanding of a specific vendor's product or technology are served well from vendor-specific training programs, but when confronted with another vendor's product they may not understand why or how it works because of a lack of instruction in fundamental theory (Zeng, 2004).

One example of a popular vendor-specific training program offered in secondary and postsecondary institutions is The Cisco Networking Academy. Cisco offers a pre-packaged online introductory networking program to prepare students for the Cisco Certified Network Associate (CCNA) certification. Cisco Systems, Inc. (2005) was founded in 1984 by a group of computer scientists from Stanford University and is currently a global leader in the development and delivery of Internet Protocol based networking technologies. As a philanthropic gesture, Cisco donated networking equipment to high schools in the region of its headquarters and several network engineers donated their time to train teachers how to use the equipment. The success of this initial gesture prompted Cisco to develop a Web-based distance-learning curriculum to train and certify secondary and post-secondary students and, in October 1997, Cisco Systems, Inc. started the Networking Academy Program (Porter \& Kramer, 2002). Porter and Kramer (2002) contended that, although Cisco's brand of philanthropy has created more social and economic value than if it had just made monetary contributions to local schools, Cisco will benefit the most because of its position as the market leader of network technologies. As of 2005, the total number of Cisco certifications awarded is estimated to be over 600,000 (CertCities, 2005).

At some cost to schools, Cisco's Networking Academy provides resources and curricular materials needed to give students a working knowledge of network configurations and an ability to diagnose and troubleshoot network problems (U.S. Department of Commerce, 2003). Carless (2005) stated that 10,372 Networking Academies have been established in fifty U.S. states and in 149 countries. The Academies operate in high schools, colleges, universities, technical schools, community-based organizations, and other educational programs encompassing a participation of more than 400,000 students. Kaminkow (2003) indicated that approximately 141,000 (US) K-12 students and 9,000 K-12 teachers are involved in the Cisco Networking Academy Program.

The Networking Academy curriculum offers students and teachers Web-based content, online assessment, performance tracking, and hands-on labs in preparation for the CCNA (Carless, 2005). Cisco has developed partner-sponsored curriculum with Sun Microsystems (Java Programming and UNIX), Adobe Systems (Web Design), Panduit (Voice and Data Cabling), and Hewlett-Packard (Hewlett-Packard). This allows students to prepare for industry-standard certifications in IT specialty areas outside of Cisco.

Cisco has made an effort to align the Networking Academy's curriculum to state and national standard frameworks for mathematics, science, and language arts by creating a standards alignment database (Tittel, 2004). Cisco Systems Inc. (2004) maintains that their standards alignment database stores the relationships between the Networking Academy course objectives and state and national standards. The methodology behind the development of Cisco's alignment database was not explicitly clear, in particular, how the data was collected to populate the database and how the alignment of learning objectives to state standards was extrapolated. 
Marie Zwickert (Testimony of Ms. Marie Zwickert, 2004), a Cisco Systems, Inc. representative, reported in a hearing before the Committee on Education and the Workforce on the importance of the federal role in supporting career and technical education programs across the U.S. In her testimony to Congress, she spoke of the success of Cisco's Networking Academy assessment system and its ability to provide immediate and on-going feedback to students and teachers about proficiencies and skills. Further, she asserted that Cisco's assessment strategy was designed to inform learning and to hold students and educators accountable for results. In Zwickert's report, no mention was made of the ability for school administrators and educators to use the assessment system to determine how many of the participating 134,682 students in the 4,000 Networking Academies in the U.S. actually get certified.

The effectiveness of a certification program on a district, state, and national level is critical to student success and the ability to make data-driven, cost-effective decisions and neither Cisco's content delivery system nor the standards alignment database provided the ability to obtain information on (1) the number of students successfully certified in a particular district or state, (2) enrollment figures for Cisco's Academy by district and state, (3) retention rate of students by district, region, and state, (4) the number of Networking Academy programs terminated at educational institutions and the reasons why, and (5) contractual obligations and program costs associated with the adoption of the Networking Academy program to include setup costs, annual maintenance, equipment replacement costs, and instructor training.

\section{Vendor-Neutral Certifications}

Prosoft Learning, Inc. (2005) defined a vendor-neutral certification as those that focus on job skills by demonstrating key concepts critical to current marketplace job roles and have core objectives that are often reinforced through popular hardware or software tools, but focus on job skills rather than software or hardware skills. Examples of vendor-neutral certifications include $\mathrm{A}+$, Server + , Network + , and CIW Associate.

Vendor-neutral certifications are developed and monitored by consortiums, nonprofit organizations, and training companies that develop standards and content through the use of committees consisting of individuals from industry, academia, and professional associations or societies. Atienza (2001) asserted that vendor-neutral certifications reflect how technologies work by focusing on concepts relative to the underlying technology, not on a particular vendor's product or proprietary technology. Further, she suggested that vendor-neutral certifications prepare individuals to work in multi-vendor environments. Tittel (2003) pointed out that although vendor-neutral exams are concept-oriented and focus on general knowledge important to practitioners a variety of vendor-specific content is covered in vendor-neutral exams reflecting the wide-spread adaptation of certain technologies.

Zarley (2004) asserted that vendor-specific certifications continue to dominate the certification market, but are fast losing ground to vendor-neutral certifications that emphasize multi-vendor skills and a solution-oriented IT environment. Roberts (2004) indicated that vendor-neutral certifications can provide an individual with core knowledge that is useful for supporting products from a variety of vendors, and not just a particular product line. Further, he suggested that there is an evolution of the certification model, one that suggests vendor-specific certifications will become specializations added to more broad-based vendor-neutral certifications. Bird (2001) notes the advantages of vendor-neutral certification programs:

1. The independence of vendor-neutral providers allows for the creation of programs and curriculum not tied to one technology or product.

2. Vendor-neutral providers offer an unbiased view, delivering a balanced coverage of topics. 
3. Vendor-neutrality allows the opportunity to address shortcomings or issues related to a product or technology.

4. Eliminating the need to promote individual products allows vendor-independent providers to focus on relevant technology issues.

5. Vendor-independent providers can develop programs that cover products from more than one manufacturer, thereby providing a more realistic perspective.

6. The generic nature of vendor-neutral certification often makes it well-suited for those new to the IT industry.

7. They provide a certification option for those who have not yet chosen a product specialization.

Atienza (2001) noted that vendor-neutral certifications have more staying power and, as an example, pointed out that both the Gartner Institute and Intel closed out their certification programs and transferred their certifications to vendor-neutral organizations for ongoing support.

The Computing Technology Industry Association (CompTIA) is the world's largest developer of vendor-neutral IT certification exams and is best known for its A+ certification. CompTIA is a not-for-profit global IT trade association representing more than 20,000 companies in 102 countries (MacKinnon, 2005). Representing the IT industry as a whole, the association is active in developing and promoting industry standards, workforce development, and influencing public policy in the area of IT. More than 600,000 people worldwide have obtained a CompTIA certification, 500,000 of which have obtained a CompTIA A+ certification (The Computing Technology Industry Association, 2005). The $\mathrm{A}+$ certification is a foundation level certification validating competency in entry-level hardware and operating systems technologies. More than 100 companies require the $\mathrm{A}+$ certification as a prerequisite to qualify for their corporate and vendorspecific training programs.

CompTIA A+ certification preparation can be found in both secondary and post-secondary institutions. Several states have purchased CompTIA membership at various levels allowing state high schools, community, technical and 4-year colleges to enter into a partnership with CompTIA. A partnership provides several benefits to include free instructor testing vouchers, job boards and discounted testing vouchers for students. Bartlett (2004) noted that although the collaborative process behind the development of the A+ reflects skills necessary for an entry-level IT job, little research has been conducted on the academic merits of the A+ certification. Further, he notes that detractors see the heavy industry focus as a concession to a more broad-based education in IT.

\section{Certification Programs Addressing Computer Literacy}

Many secondary and several community colleges are addressing their needs for a standardized set of computer literacy standards by turning to two organizations that offer a globally accepted certification in computer literacy; the International Computer Driving License (ICDL) and the Internet and Computing Core Certification $\left(\mathrm{IC}^{3}\right)$. Although these certifications are globally recognized, they are only intended to provide introductory computer skills as a starting point to higher level certifications or studies in information technology.

\section{International Computer Driving License}

The ICDL Federation is an internationally recognized non-profit organization that is based in Europe and has set the standard in computer literacy. ICDL provides a vendor-neutral IT certification that is supported and monitored by an international panel of subject matter experts. The 
ICDL certification is available in 138 countries with over 4 million participants with 12 million tests taken and endorsed by over 50 international bodies and computer societies (European Computer Driving License Foundation, 2005). Csapo (2002) asserted that the ICDL could provide a computer literacy standard that could eliminate gaps in knowledge and provide teachers with a common set of standards from which to validate student IT skills.

\section{Internet and Computing Core Certification}

The Internet and Computing Core Certification $\left(\mathrm{IC}^{3}\right)$ issued by Certiport, Inc. has attempted to establish a global standard for measuring basic computing literacy. $\mathrm{IC}^{3}$ provides students and teachers with a credential that establishes a level of computer competence. Certiport developed their $\mathrm{IC}^{3}$ computer literacy standards by polling data from testing centers on market needs, working with subject matter experts to establish the measurement criteria, and working with academia, business, and government in 19 countries to define computer literacy standards. Certiport continuously monitors standards through ongoing analysis, subject matter expert input, and beta testing. Certiport's IC $^{3}$ certification can be used as an effective way to satisfy state and local computer literacy standards in addition to serving as an assessment benchmark for higher-level IT certifications (Certiport, Inc., 2005).

\section{The IT Workforce and its Implications for IT Certification}

In order to understand the increasing role of technology in formal education and the implications for students, an understanding of the current IT workforce, future employment projections, and the appropriate education and training for employment is necessary. In 2004, the U.S. Bureau of Labor Statistics (BLS) reported that between 2002 and 2012 the IT industry is projected to have a $68 \%$ increase in growth rate and add 632,000 new jobs (U.S. Department of Labor, 2004). Increased growth will be a result of rapid advances in computer technology, software applications, and the growing significance of information security. BLS employment projections indicated that seven of the thirty fastest growing occupations are expected to be IT-related, with an average growth rate of $43 \%$, and all seven requiring a bachelor's degree.

The Information ITAA Annual Workforce Development Survey (ITAA, 2004) reported major findings on trends in the IT workforce. The study found that hiring managers preferred a combination of previous experience (46\%) and a four-year degree (41\%), both in a related field. As a background discriminator, vendor certifications showed to be of lower importance in the hiring process (14\%) and carrying different degrees of importance depending on the specific IT job role. Interpersonal skills were the highest rated non-technology skill cited by $52 \%$ of the hiring managers polled in the survey as being important to the hiring process. ITAA data indicate that 213,639 IT workers were added to the workforce in 2004 and approximately $89 \%$ of the hires were added by non-IT companies with $72 \%$ of all IT jobs being occupied by workers in small companies.

Many entry-level IT certification programs offered in a formal education setting are meant to prepare students for computer support roles or related services. Employment for individuals with computer support skills is expected to increase faster than the average for all occupations through 2012 as a result of continued incorporation of technology into critical business operations (U.S. Department of Labor, Bureau of Labor Statistics, 2005). According to BLS data there is a preference by employers to hire people for computer support roles that have some post-secondary education. Further, BLS emphasizes that many employers in demand of a certain skill set will overlook a formal degree in exchange for an individual with prior experience and relevant IT certification. BLS stressed that job prospects for computer support specialists and system administrators will be optimal for individuals holding both a formal degree and supplemental work experience, but noted that those not holding a formal degree can still qualify for entry-level positions with the right certification and previous work experience. 
In contrast, when proprietary IT vendor programs are employed in formal education settings, a number of salient issues arise that directly effect students and schools participating in these programs. The U.S. Department of Commerce (2003) emphasized some of the chief concerns with IT certifications. One of the largest barriers that a student faces when trying to gain entry-level IT employment is a lack of experience in application of skills. Students participating in an IT certification program in a career and technical school or in a community college often progress through the programs without the benefit of an internship, resulting in lack of experience and lost job opportunities. Many vendor-specific certification programs are too focused on a particular vendor's product and test preparation and fail to integrate a vendor's products with different technologies. IT certification programs focused on a particular vendor's product or technology loose currency as technology lifecycles mature and do not develop foundational knowledge and skills needed for upward mobility in an IT career. Certifications are commonly looked upon as satisfying the criteria for entry-level IT jobs, or the immediate technical needs of employers, but without some postsecondary education, and experience certifications are considered inappropriate preparation for more complex IT work.

Freeman and Aspray (1999) indicate that although the vast majority of IT workers do not obtain formal degrees in IT-related disciplines, bachelor's degree programs still produce the largest number of graduates for the IT workforce. U.S. Department of Commerce (2003) data indicated that two thirds of IT workers have at least a four year degree and that employers generally seek candidates with a post-secondary education for professional-level IT jobs. The BLS projects that, between 2000 and 2010, almost three-quarters of the job openings for professional-level IT workers will be in occupations that typically require at least a bachelor's degree. Although many employers hire workers with a particular certification to satisfy a specific technical skill set, such preparation alone is not adequate for an employee to obtain mid- to high- level positions (U.S. Department of Commerce, 2003).

\section{Who Benefits?}

Partnerships between IT vendors and formal education institutions are becoming more common as the demand grows for transient, portable IT skills. Educational institutions benefit by gaining access to ready-made, industry-sponsored IT curriculums that are responsive to workforce needs and easily aligned to state and national IT standards.

There is also a growing trend for states to enter into partnerships or memberships with vendors and associations, such as Prosoft Learning Corporation and CompTIA, in return for the right to utilize proprietary curriculum materials and gain benefits that aid in the implementation of industry-based skill standards and IT certifications. As of June, 200515 states have purchased a membership to CompTIA gaining benefits for associated member's state high schools and colleges (CompTIA, 2005). The Arkansas Department of Workforce Education selected the CIW program to provide a statewide standardized IT curriculum and certification in Web technologies for both secondary and post-secondary institutions. Prosoft will provide Arkansas secondary and postsecondary schools with curriculum, assessment tools, and classroom exam delivery. The State of Tennessee Department of Education has also partnered with Prosoft to integrate Prosoft's CIW Web Site Foundations, Web Page Design - Site Designer, and E-Commerce curriculum into 200 of the state's public secondary schools in 2006 (Prosoft Learning, Inc., 2005).

A vendor that successfully introduces their curriculum into a classroom benefits by gaining an allegiance of trained workers to support their product, service, or technology (Computer Science and Telecommunication Board, 2001). Bartlett (2002) indicated that IT certifications may act to satisfy not only the training needs to support the products and services of a company, but they also act to increase a vendor's market share and revenue. Students working with a particular vendor's software, hardware, and proprietary curriculum over a period of time may develop a prefer- 
ence for a particular product and ultimately promote that brand of technology out in the workforce. According to Brookshire (2000), IT certifications play an important role for both students that use the skills to get employment and institutions, such as career and technical schools, that need to attract and place students. He noted that certifications are also important to the vendors that create them as a way to promote the widespread adoption of their products and technologies.

Ray and McCoy (2000) emphasized the benefits that certifications provide to students, employers, and educational institutions, but noted the debate over the value of certifications in a formal education given the rapid changes in technology and associated changes in the knowledge base. Technical skills depreciate quickly and hardware and software technologies have short lifecycles making it difficult for educational institutions to deliver IT education and accommodate workforce needs (U.S. Department of Labor, 2004). IT certifications are market-driven and skills learned by students while pursuing an IT certification become dated as the IT market or life-cycle of the hardware or software changes.

\section{Conclusions and Recommendations}

This paper presented issues surrounding the use of IT certification programs and IT certification preparation in both secondary and post-secondary education. Adelman (2000b) pointed out that an accurate count of IT certifications issued worldwide is difficult to determine because there are no entities charged with the responsibility of maintaining either duplicated or unduplicated headcounts. Likewise, there are no national or state centralized data collection efforts surrounding IT certification programs in formal education settings that can attest to or account for the numbers of students attempting, failing, or passing IT certification exams after enrollment in a course of study designed to prepare students for the exam.

In an effort to make informed decisions about IT certification programs, school administrators and IT teachers need adequate information on current IT workforce trends, IT certification programs used in formal education, and performance data on students enrolled in these programs. A solid grasp of future IT workforce indicators will serve as an aid to IT educators and administrators in initiating or phasing out ineffectual certification programs. IT educators, administrators, and state education decision makers need a centralized source of information that will provide details on:

1. Current workforce indicators related to projected labor demands and skill shortages in IT related occupations.

2. The number and types of IT certifications programs currently in place in secondary and post-secondary schools.

3. The number of students enrolled in each certification program by district and state.

4. The number of secondary and post-secondary students successfully certified on an annual basis for each type of IT certification program by district and state.

5. Retention rate of students in each type of IT certification program broken down by district and state.

6. The number and types IT certification programs terminated or initiated by district and state and the reasons for each.

7. The IT certification program costs and contractual obligations by vendor or association.

8. A listing of post-secondary institutions offering IT certification preparation, or IT certification programs broken down by type of certification. 
A critical need to collect and share program and student data exists as demonstrated by Dede's (2001) State Policy Framework for Assessing Educational Technology. Dede developed the framework as an aid to state education decision makers in assessing educational technology implementation (Dede, 2001). The framework suggests ways that state policy can influence educational technology and data mining to improve student learning, and it presents essential questions that highlight issues. The following essential questions raised in Dede's (2001) policy framework point out the need for states to address program accountability and standards alignment:

1. Does the State provide districts and colleges with information for each school synthesized in a manner that facilitates making educational policies and decisions?

2. Does the State encourage districts to collect student and financial data in ways that facilitate sharing information and providing comparative analyses across districts?

3. Does the State provide financial incentives for districts and colleges to participate in data-based decision making? (p. 3)

The lack of a centralized data source on IT certification programs that can assist in making datadriven decisions or facilitating analysis of certification programs across and within districts prevents administrators and IT teachers from making informed choices in the interest of students. In an effort to make informed decisions about IT certification programs, school administrators and IT teachers need adequate information on current IT workforce trends, IT certification programs used in formal education, and performance data on students enrolled in these programs.

The following questions should be answered before an administrator or IT teacher makes a decision on implementing an IT certification program or IT certification preparation:

1. What are the current workforce trends and projected labor demands for IT related occupations? Will a student benefit from obtaining an IT certification based on current workforce needs?

2. Is the IT certification program or certification preparation appropriate for the educational level of the students?

3. Will the students benefit more from a vendor-neutral or vendor specific IT certification program? Will the students benefit more from a certification program that focuses on foundational concepts or on a particular vendor's product?

4. What value will an IT certification add to a student's education and chances for success?

5. What program and student data is available on IT certification from other educational institutions?

6. What are the costs and contractual obligations associated with implementation and maintenance of an IT certification program?

7. What are the costs to the students?

\section{Summary}

This paper summarized the different issues surrounding the use of information technology certifications in formal education settings with a focus on school administrators and IT educators who may be exploring options for IT programming. It is the author's belief at this time that additional information, by way of structured research, is needed to determine the efficacy of such programs in secondary and post-secondary institutions. Investments in these types of certifications are both 
cost and time-intensive, and school administrators and IT educators need valid data from which to make decisions.

\section{References}

Adelman, C. (2000a). A parallel postsecondary universe: The certification system in information technology. Jessup, MD: U.S. Department of Education, Office of Educational Research and Improvement.

Adelman, C. (2000b). A parallel universe, expanded: Certification in the information technology guild [Electronic version]. Change, 32(3). Retrieved February 5, 2005, from http://www.aahe.org/change/paralleluniverse.htm

Al-Rawi, A., Lansari, A., \& Bouslama, F. (2005). Integrating Sun certification objectives in to an IS programming course. The Journal of Issues in Informing Science and Information Technology, 2, 247257. Retrieved July 15, 2005, from http://2005papers.iisit.org/I20f39Rawi.pdf

Andero, A. (2001). The changing role of school superintendent with regard to curriculum policy and decision making. Education, 121(2), 276-286.

Atienza, C. (2001, September). The right mix of IT certifications. Certification Magazine. Retrieved February 2, 2005, from http://www.certmag.com/issues/sep01/feature atienza.cfm

Barron, A. E., Kemker, K., Harmes, C., \& Kalaydjian, K. (2003). Large-scale research study on technology in K-12 schools: Technology integration as it relates to the National Technology Standards. Journal of Research on Technology in Education, 35(4), 489-507.

Bartlett, K. (2002). The perceived influence of industry-sponsored credentials in the information technology industry. St. Paul, MN: University of Minnesota, National Research Center for Career and Technical Education.

Bartlett, K. (2004). The signaling power of occupational certification in the automobile service and information technology industries. St. Paul, MN: University of Minnesota, National Research Center for Career and Technical Education.

Bird, D. (2001). Certified paths to success. Certification Magazine. Retrieved May 1, 2005, from http://www.certmag.com/issues/mar01/feature bird.cfm?printversion=1

Brookshire, R. (2000). Information technology certification: Is this your mission? Information Technology, Learning, and Performance Journal, 18(2), 1-2.

Cantor, J. (2002). Skills certifications and workforce development: Partnering with industry and ourselves [Electronic version]. Leadership Abstracts, 15(1). Retrieved March 22, 2005, from http://www.league.org/publication/abstracts/leadership/labs0102.html

Carew, D., \& Flynn, W. (2002). The new sheepskin. Community College Journal, 6, 9-12.

Carless, J. (2005). Cisco networking academy program: Five-year fast facts. Retrieved May 30, 2005, from http://newsroom.cisco.com/dlls/hd 040303.html

Carnevale, A. P., \& Desrochers, D. M. (2001). Help wanted . . credentials required: Community college in the knowledge economy. Princeton, NJ: Educational Testing Service.

Cegielski, C. (2004). Who values technology certification? Communications of the ACM, 47(10), 103-105.

Cegielski, C., Rebman, C., \& Reithel, B. (2003). The value of certification: An empirical assessment of the perceptions of end-users of local area networks. Information Systems Journal, 13, 97-107.

CertCities. (2005). Cisco certified network professional. Retrieved May 30, 2005, from http://certcities.com/certs/other/cert.asp?ID $=15$

Certiport, Inc. (2005). Internet and computing core certification (IC $\left.{ }^{3}\right)$. Retrieved May 30, 2005, from http://www.certiport.com/Portal/desktopdfault.aspx?tabid=229\&roleid=102 
Information Technology Student-Based Certification

Cisco Systems, Inc. (2004). Standards alignment database. Retrieved May 30, 2005, from http://standards.netacad-currdev.net/home/default.asp

Cisco Systems, Inc. (2005). Program overview - CCNA FAQs. Retrieved May 30, 2005, from http://www.cisco.com/en/US/learning/netacad/course_catalog/CCNAFAQ.html

Clarke, B. (2001, July). Corporate curricula in schools: issues and implementation. Paper presented at the meeting of the Seventh World Conference on Computers in Education, Copenhagen, Denmark.

The Computing Technology Industry Association, Inc. (2005). About CompTIA. Retrieved May 30, 2005, from http://www.comptia.org/about/default.aspx

Computer Science and Telecommunications Board. (2001). Building a workforce for the information economy. Washington D.C.: National Academy Press.

Csapo, N. (2002). Certification of computer literacy: The international computer driving license provides standards that let individuals participate in a global digital society. T.H.E. Journal, 30(8), 46-51.

Dede, C. (2001). State policy framework for assessing educational technology implementation: Version 4. Boston, MA, Harvard University.

The European Computer Driving License Foundation. (2005). About the ECDL Foundation. Retrieved April 26, 2005, from http://www.ecdl.com/main/about.php

Freeman, P., \& Aspray, W. (1999). The supply of information technology workers in the United States. Washington D.C.: Computing Research Association.

Information Technology Association of America. (2004, September). Adding value ... Growing careers: The employment outlook in today's increasingly competitive IT job market. Arlington, VA: Author.

International Society for Technology in Education. (2004). ISTE national educational technology foundation standards for all students. Eugene, OR: Author. Retrieved April 11, 2005, from http://cnets.iste.org/students/s stands.html

Kaminkow, J. (2003, July). Cisco networking academy tool. Project presented at the annual ISTE Assessment and Technology Forum, Seattle, Washington. Retrieved May 30, 2005, from http://216.25.8.18/portfolioessentials/2003/2 cisco.htm

Koziniec, T.W. \& Dixon, M.W. (2002, June). ICT industry certification: Integration issues for postsecondary educational institutions in Australia. Proceedings of the 2002 Informing Science and IT Education Conference, Cork, Ireland. 831-838. Retrieved from http://proceedings.informingscience.org/IS2002Proceedings/papers/Kozin173ICT.pdf

MacKinnon, C. (2005). Professional IT associations: What do you get out of membership? Processor, $27(1), 30$.

Minch, R. \& Tabor, S. (2003). Networking education for the new economy. Journal of Information Technology Education, 2, 51-59.

National Workforce Centers for Emerging Technologies. (2003). Building a foundation for tomorrow: Skill standards for information technology. Bellevue, WA: Author.

Porter, M., \& Kramer, M. (2002, December). The competitive advantage of corporate philanthropy. Harvard Business Review, 5-16.

Prosoft Learning, Inc. (2005). Prosoft Learning. Retrieved May 30, 2005, from http://www.prosoftlearning.com/certassess/ciw.asp

Ray, C., \& McCoy, R. (2000). Why certification in information systems? Information Technology, Learning, and Performance Journal, 18(1), 1-4.

Roberts, J. (2004, August 27). 2004 certification study: The new deal. CRN. Retrieved March 22, 2005, from http://www.crn.com/sections/special/certification/certification.jhtml? ArticleID $=42700080$ 
Roblyer, M. D. (2000). The national educational technology standards (NETS): A review of definitions, implications, and strategies for integrating NETS into K-12 curriculum. International Journal of Instructional Media, 27(2), 133-146.

Rowe, J. (2003, April). IT certifications: lessons from other industries. Certification Magazine. Retrieved July 15,2005 , from http://www.certmag.com/articles/templates/cmag_issue_toc.asp?articleid=169\&zoneid=59

Sands, C. (2003). Techie training for students. Tech Learning. Retrieved February 02, 2005, from http://www.techlearning.com/story/showArticle.jhtml?articleID=15202086

Testimony of Ms. Marie Zwickert. (2004, April 27). Hearings before the Subcommittee on Education Reform, of the House Committee on Education and the Workforce, $108^{\text {th }}$ Congress. Retrieved April 22, 2005, from http://edworkforce.house.gov/hearings/108th/edr/voced042704/zwickert.htm

Thompson, B. (2003). Information technology courses in northern Illinois high schools: An evaluation of Cisco Academy curriculum in high school information technology programs. Unpublished masters thesis, University of Illinois, Springfield.

Tittel, E. (2000). Charting the certification business. Certification Magazine. Retrieved March 22, 2005, from http://www.certmag.com/issues/nov00/feature tittell.cfm

Tittel, E. (2003, October) Studying for vendor-neutral versus vendor-specific exams. Certification Magazine, 50-51.

Tittel, E. (2004, March 5). IT certification in academia: An overview and survey. Retrieved March 22, 2005, from http://www.quepublishing.com/articles/article.asp?p=169635

U.S. Department of Commerce. (2003). Education and training for the information technology workforce: Report to Congress from the Secretary of Commerce. Washington D.C.: Author.

U.S. Department of Labor, Bureau of Labor Statistics. (2004, February 11). February 2004 Monthly Labor Review Table 3. Retrieved December 23, 2004, from http://www.bls.gov/emp/emptab3.htm

U.S. Department of Labor, Bureau of Labor Statistics. (2005). Occupational outlook handbook: Computer and mathematical occupations. Washington D.C.: Author.

Zarley, C. (2004). Solution provider sentiment swings toward neutral programs. CRN. Retrieved May 28, 2005, from http://www.crn.com/sections/special/certification/certification.jhtml? ArticleID=42700078

Zeng, F. (2004). A new approach to integrate computer technology certification into computer information system programs. Proceedings of the 2004 American Society for Engineering Education Annual Conference and Exposition, Salt Lake City, Session 2558. Retrieved July 19, 2005 from http://www.asee.org/acPapers/2004-1708_Final.pdf

Ziob, L. L. (2000). Time is flying: 10 years of IT certifications. Certification Magazine. Retrieved April 30, 2005, from http://www.certmag.com/issues/feb00/features.cfm

\section{Biographies}

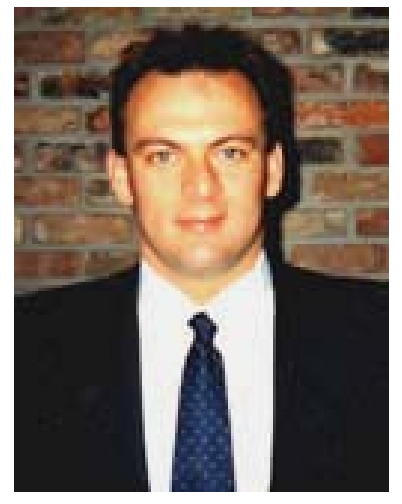

Michael Randall is currently a Ph.D. candidate in Workforce Development and Education within the College of Education at The Ohio State University. He earned his bachelor degree from the University of Houston and his masters from The Ohio State University. Currently, he holds a CCNA certification and teaches information technology courses at an area career center. He also teaches professional development courses as an adjunct faculty for Ashland University. Before teaching and pursuing his Ph.D., he worked in the IT industry for several years as a programmer/systems analyst on a variety of projects. 


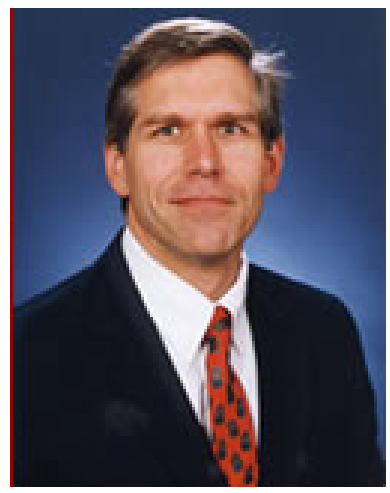

Dr. Chris Zirkle is an Assistant Professor in Workforce Development and Education within the College of Education at The Ohio State University. He received his Ph.D. in Education from The Ohio State University. He is the primary advisor for the teacher licensure programs in Integrated Business Education and Career and Technical Education and is a member of the Ohio State University Teacher Education Council. He also serves as the Ohio State representative on the University Council for Workforce and Human Resource Education. His research interests include the integration of technology in instruction and the utilization of distance education in teacher education programs. 